\title{
A REVISTA EDUCAÇÃO \& SOCIEDADE: UMA LEITURA DOS EDITORIAIS DE 1978 A 1996*
}

\author{
Fabiana de Cássia Rodrigues ${ }^{1}$
}

\begin{abstract}
RESUMO: O texto analisa os editoriais da Revista Educação \& Sociedade n. 1 a 57, abarcando o período entre 1978 e 1996. Percebese esta publicação como um corpus documental que expressa diferentes concepçóes educacionais e perspectivas políticas, que, em conexão com a ebulição no campo educacional no período, traz luz para amplas possibilidades de estudos oferecidas por este acervo. Procurou-se colocar em destaque o contexto de surgimento da Revista como expressão política de um grupo de intelectuais engajados na luta pela educação na construção de uma sociedade democrática. A Revista também se constituiu como um importante espaço de confronto de ideias, tornandose uma referência fundamental para o estudo dos dilemas e desafios educacionais da realidade brasileira. $\mathrm{O}$ texto está organizado em três partes: inicialmente, a Revista é discutida como um espaço de consenso no rechaço à ditadura e à sua política educacional. $\mathrm{Na}$ segunda parte do texto destacam-se aspectos que exemplificam o intenso debate em que a Revista estava inscrita, como lugar de divergências teóricas e políticas. Por fim, na terceira parte, são tratados aspectos que se sobressaíram na análise dos editoriais na "Nova República": o debate sobre a Lei de Diretrizes e Bases (LDB), as relaçóes entre educação e trabalho, em meio às políticas de cunho neoliberal, e o processo de reestruturação produtiva.
\end{abstract}

Palavras-chave: Revista Educação \& Sociedade. Editoriais. Educação. Democracia.

\section{THE JOURNAL EDUCAÇÃO \& SOCIEDADE: A READING OF EDITORIALS FROM 1978 TO 1996}

\begin{abstract}
The text analyses the editorial of the Magazine Education and Society issues 1 to 57, encompassing the period between 1978 and 1996. This publication is perceived as a documentary corpus that expresses both different educational concepts and political perspectives that, in connection with the ebullience in the educational field during
\end{abstract}

\footnotetext{
*Este artigo se vincula ao projeto de pesquisa: "A história da luta pela educação pública nas publicaçóes do Centro de Estudos Educação e Sociedade (CEDES), Associação Nacional de Educação (ANDE) e Associação Nacional de Pós Graduação e Pesquisa em Educação (Anped), na década de 1980." ${ }^{1}$ Universidade Estadual de Campinas, Departamento de Filosofia e História da Educação - Campinas (SP), Brasil. E-mail: fabicassia@yahoo.com.br DOI: 10.1590/ES0101-73302018190171
} 
such period, sheds light on the broad possibilities of study provided by this collection. The context in which the journal emerged was put in the spotlight as a political expression of a group of intellectuals engaged in the fight towards education and the building of a democratic society. The journal is also an important space for clash of ideas, thus being an essential reference for the study of dilemmas and educational challenges of the Brazilian reality. This article is organized in three sections: initially, the journal is referred to as a space of consensus about rejection of both dictatorship and its educational policies. The second part of the text highlights some aspects that exemplify the intense debate in which the journal was inserted, as a place for theoretical and political divergences. Finally, in the third section, aspects standing out from the editorials addressing the "New Republic" are approached: a debate about LDB, the relationship between education and work amongst neoliberal policies, and the process of productive restructuring.

Keywords: Journal Educação \& Sociedade. Editorials. Education. Democracy.

\section{LA RÉVUE EDUCAÇÃO \& SOCIEDADE: UNE LECTURE DES ÉDITORIAUX DE 1978 À 1996}

RÉSUMÉ: cete article analyse les éditoriaux de la revue Educação \& Sociedade, éditions 1 à 57, englobant la période entre 1978 et 1996. Cette publication est perçue comme un corpus documentaire qui exprime des conceptions pédagogiques et des perspectives politiques différentes, lesquelles, en rapport avec l'ébullition dans le domaine de l'éducation de cette période, éclaire les larges possibilités drétudes permis par cet assortiment. En visant à mettre en évidence le contexte de lémergence de la Révue, en tant quexpression politique d`un groupe dintellectuels engagés dans la lutte pour leéducation pour la construction d'une société démocratique. La revue, également, constituait un importante espace de confrontation d'idées, en devenant une référence fondamentale pour l'étude des dilemmes et des défis éducatifs de la réalité brésilienne. Le texte est organisé en trois parties: d'abord, la revue est débattue comme une place de consensus en repoussant la dictature et sa politique d'éducation. Dans la deuxième partie, soulignent certains aspects qui illustrent un débat intens dans lequel la revue se trouve, en tant que lieu des divergences théoriques et politiques. Enfin, dans la troisième partie, on aborde des aspects qui se démarquant de l'analyse des éditoriaux de la "Nouvelle République": le débat sur la LDB, les rapports entre éducation et travail, face des politiques néolibérales et le processus de restructuration productive.

Mots-clés: Revue Educação \& Sociedade. Editoriaux. Éducation. Democracie. 


\section{Introdução}

$1 \begin{aligned} & \text { Revista Educação \& Sociedade constituiu uma das expressóes da reorganiza- } \\ & \text { ção da luta pela educação pública ao final dos anos 1970, no refluxo do que } \\ & \text { Florestan Fernandes (2006a) denominou "contrarrevolução". Após cerca }\end{aligned}$ de 15 anos de regime ditatorial, a crise econômica e política que o país atravessava debilitava crescentemente o poderio militar, juntamente com a intensificação da mobilização de trabalhadores de diversos setores que culminaram em greves na indústria, nas escolas, luta pela terra, e reivindicações por direitos em saúde e educação.

No início dos anos 1980, todo o campo progressista unia-se em torno de uma palavra de ordem irretorquível — "diretas-já” —, que visava restabelecer o direito ao voto. Em resposta ao movimento das diretas, por meio de estratégias de conciliação, a ditadura construiu uma transição lenta, gradual e segura e boicotou a transição democrática, culminando na eleiçáo do novo presidente da República pelo colégio eleitoral. Apesar desta condução do processo político pelo tope, a ditadura, por outros meios, não logrou impedir o forte avanço das lutas sociais em diferentes âmbitos:

A burguesia que resistira tenazmente a todas as reformas e revoluções
intrínsecas ao desenvolvimento capitalista deparou com uma trans-
formação que conseguiu sabotar e deter, mas não logrou impedir. As
classes trabalhadoras da cidade e do campo apareciam como agentes
históricos, e as insatisfaçóes acumuladas - do índio e do negro à
pequena burguesia enraivecida e aos setores tradicionais radicalizados
das classes médias - compunham um vasto arco histórico, pelo qual
se alteravam os rumos da história no fim do século XX. O êxito da
conspiraçáo forjada pelo alto dos estratos dirigentes das classes pos-
suidoras prendeu esse arco à revolução dentro da ordem, mas sob um
alto preço histórico: a revoluçáo democrática, a revoluçâao nacional, a
reforma agrária e outras transformaçóes estruturais são impelidas para
a frente, através da luta de classe dos de baixo, dos oprimidos e dos su-
balternizados, o que estabelecia um nexo, que não pode ser ignorado,
entre reforma e revolução (FERNANDES, 2006b, p. 109).

Voltava à cena histórica a luta pelo conjunto de reformas, entre elas a educacional, que compunha a revolução democrática e nacional, abafada e reprimida na contrarrevolução representada pelos governos militares a partir de 1964.

Nos momentos decisivos da revolução burguesa no Brasil, nos anos 1950 e início dos anos 1960, estava presente no debate nacional a discussão sobre os papéis que a educação pública deveria cumprir no desenvolvimento do capitalismo no país. Tratava-se de enfrentar as altas taxas de analfabetismo que ultrapassavam os $50 \%$ da população e da construção de um sistema nacional de educação que garantisse homogeneidade à educação pública ao conjunto da população brasileira (FERNANDES, 2006a). Seriam essas condiçóes fundamentais para lançar no país as bases de 
uma efetiva democracia. As organizaçóes políticas desse período, que permeavam a sociedade civil e o Estado, colocaram-se em defesa tanto da educação popular, cujas expressóes mais significativas puderam se evidenciar no movimento de educação de base (MEB), que adotou o método Paulo Freire e foi erigido à política pública no governo Joáo Goulart, quanto no movimento em defesa da escola pública, em meio às tensóes na formulação da primeira Lei de Diretrizes e Bases (LDB). Neste contexto, tratava-se de reivindicar a escola pública, laica e estatal, bem como garantir que os recursos públicos fossem direcionados exclusivamente à escola pública.

Ao final dos anos 1970, retornaram ao debate educacional os dilemas e desafios fortemente discutidos no período anterior à ditadura, a questão do analfabetismo, das verbas públicas para a escola pública, das relaçóes entre educação e democracia.

Ao mesmo tempo, este era um novo momento histórico em que a posição dos trabalhadores na sociedade civil mudara profundamente:

A incorporação ao núcleo do capitalismo monopolista, a industrialização maciça e o aprofundamento da penetração do desenvolvimento capitalista no campo, principalmente, modificaram substancialmente os números, a forma e os dinamismos do regime de classes sociais (FERNANDES, 2007, p. 180).

Neste mesmo movimento da história, incluiu-se a "proletarização dos professores". Assim como as exigências da industrialização se conectaram ao tecnicismo educacional expresso na reformulação da LDB, na Lei no 5.692/1971, a nova legislaçáo trouxe também a extensão da obrigatoriedade escolar de quatro para oito anos, resultando em uma ampliação quantitativa das escolas, o que exigiu maior número de professores, simultaneamente ao arrocho salarial desses profissionais (CUNHA, 1991). $\mathrm{O}$ aumento quantitativo de professores, bem como seu rebaixamento social caracterizam mais fortemente sua condição de proletário e contribuem para explicar a organização política dessa categoria no mesmo período (FERREIRA JR.; BITTAR, 2006).

Essas circunstâncias conectaram-se ao aparecimento da Revista Educação \& Sociedade, que surgiu, inicialmente, em 1978, como publicação da Faculdade de Educação da Universidade Estadual de Campinas (UNICAMP) e já em seu segundo número, de janeiro de 1979, torna-se incumbência do Centro de Estudos Educação \& Sociedade (CEDES), ponto de integração de educadores de variadas instituiçóes:

Por corresponder aos anseios de muitos, não podíamos deixar esse veículo de manifestaçáo de pensamento e de ação ligado apenas a um pequeno grupo dentro de uma instituição. Por isso, E\&S passa a ser um ponto de integração e de associação de todos os educadores que queiram retomar a educação na perspectiva de suas relaçóes com a sociedade. Esforços no sentido de reuni-los num centro - que provisoriamente chamamos "Centro de Estudos Educaçáo e Sociedade (CEDES)” - já estão sendo feitos (EDUCAÇẤO \& SOCIEDADE, 1979a). 
De um lado, há uma convergência fundamental que está na base do surgimento da Revista e corresponde à luta dos educadores contra a ditadura. Por outro, o periódico se apresenta como um espaço de debates de ideias no âmbito da educação, congregando proeminentes intelectuais que encontram na Revista lugar para o rico enfrentamento teórico e político. Esse duplo aspecto da publicação está expresso no editorial da Revista de número 3:

A revista Educação \& Sociedade foi lançada com o intuito de promover um amplo debate da educaçáo brasileira, tendo como seu cerne a luta contra a educação do colonizador, que é a nossa educação dominante, e propor uma educaçáo que não seja apenas interrogativa, crítica, mas que seja afirmativa, na busca de alternativas válidas (EDUCAÇẨO \& SOCIEDADE, 1979a, p. 3).

Após a primeira metade da década de 1980, a sociedade brasileira vivenciou um novo contexto com o fim da ditadura bastante diferente do almejado pelos setores mais progressistas, pois não houve a possibilidade de eleições diretas que poderiam significar uma real ruptura com a ditadura, tampouco foi eleita uma Assembleia Nacional Constituinte livre e soberana. Florestan Fernandes chamou a atençâo para essas derrotas e aos desafios colocados já em 1985, em um artigo intitulado Golpes dentro dos Golpes, ele escreveu:

O poder concentrado no tope só se reproduz sob a condição de um controle ativo, vigilante e persistente que impeça qualquer abalo da "tradição" de concentração do poder. Os de cima manobram constantemente para prevenir tal eventualidade, sob as formas previsíveis (FERNANDES, 2007, p. 89).

O desafio consistia na carência de um regime político que organizasse "um Estado democrático com múltiplas vozes e valores divergentes" (FERNANDES, 2007, p. 89).

Assim, nas edições da segunda metade da década de 1980 até 1996 percebe-se uma forte presença dos debates em torno do capítulo da educação na nova Constituição promulgada em 1988, e sobre a nova LDB. No entanto, neste cenário político que expressou a intensificação das lutas sociais, a condução à "Nova República" foi extremamente difícil, reproduzindo limites da sociedade antidemocrática, impingindo óbices significativos à consecução de uma ampla reforma educacional fundada na escola pública, laica, estatal e gratuita em todos os níveis, garantida por meio da premissa básica de que as verbas públicas privilegiariam exclusivamente a educação pública. Nesse período, o tom da revista não se volta à crítica contundente contra o Estado, tal como no período ditatorial, ela torna-se espaço primordial dos debates em torno da legislaçẫo que daria as diretrizes para a educação brasileira nesta "Nova República". 
A discussão sobre o Estado reaparece a partir de 1990, com as reformas neoliberais perpetradas a partir daí, com Fernando Collor de Mello, Itamar Franco e Fernando Henrique Cardoso. Nesse período, um dos temas de destaque da revista foi a discussão entre educação e trabalho, em meio à reestruturação produtiva.

Desse modo, o texto está organizado em três partes. Inicialmente, a revista será discutida como um espaço de consenso no rechaço à ditadura e à sua política educacional. Na segunda parte do texto destacam-se alguns aspectos que exemplificam o intenso debate em que a Revista estava inscrita, como espaço de divergências teóricas e políticas. As ediçóes da Revista Educação \& Sociedade constituem um corpus documental que expressa diferentes concepçóes educacionais e de perspectivas políticas, percebê-lo em sua conexão com a ebuliçáo que ocorria no campo educacional no período traz mais luz para a riqueza oferecida por este acervo. Por fim, na terceira parte, são tratados aspectos que se sobressaíram na análise dos editoriais na "Nova República", período assinalado por significativas derrotas políticas e por algumas conquistas por parte da luta dos educadores. A partir de 1989 destaca-se nos editoriais a organizaçáo dos educadores na discussão sobre a LDB em elaboração. Assim como adquire centralidade nas publicaçóes a temática que articula educação e trabalho, segundo os desafios lançados ao pensamento científico a respeito das novas tecnologias de produção e pelas políticas de cunho neoliberal, no curso do processo de reestruturação produtiva.

\section{A Revista Educação \& Sociedade e um consenso: a luta contra a ditadura no refluxo da contrarrevolução}

O período militar atribuiu respostas totalmente diversas a qualquer feição democrática e emancipadora à educação brasileira. Os professores e pesquisadores da educação que passaram a se organizar nessas circunstâncias se uniram em torno de um consenso que correspondia ao rechaço à política educacional tecnicista, inspirada na teoria do capital humano. No editorial comemorativo da revista número 50, o professor Evaldo Vieira destaca esse aspecto que caracteriza o surgimento da Revista:

\footnotetext{
Nascida e criada em ocasião pouco propícia à livre manifestação do pensamento, nada afeita ao tecnicismo educacional vigente e glorificado, ao burocratismo escolar, ao formalismo teórico e ao ideal apolítico dos educadores tranquilos, a Revista ganhou a respeitabilidade dos interessados em Educação, em Cultura, em Ciências Humanas (VIEIRA, 1995, p. 10).
}

Assim, chegamos a um aspecto essencial para caracterizar os primeiros anos da revista, já destacado por Vieira (1995, p. 10):

Durante esse tempo, predominou a crítica ao Estado Militar, à ditadura, às políticas sociais e às políticas educacionais na revista 
Educação \& Sociedade, dando primazia à análise do funcionamento do aparelho estatal, das relaçóes do Estado com a escola, com o analfabetismo, com os diferentes níveis de ensino, tipos de educação. [...] Trata-se de admitir que o exame e a crítica do Estado Militar no Brasil, e das relaçóes orgânicas entre as atividades educacionais e a ditadura, monopolizaram, em grande parte, as atençóes e os esforços de articulistas comprometidos com a democracia, com a liberdade, com a cidadania, com a educação para todos, com a igualdade social. A Revista bem espelha as inquietaçóes de muitos professores e intelectuais desde 1978, ano de seu aparecimento, sendo fiel às questóes de seu momento histórico, traduzindo em suas páginas os dilemas, as contradiçôes e as alternativas cabíveis.

Como expressão do rechaço ao regime militar e à política educacional da ditadura, pode-se verificar que até o número 18 as Revistas tiveram seguidamente títulos gerais, que correspondiam a verdadeiros chamamentos aos professores para que se engajassem na luta, assim como anunciavam um forte conteúdo crítico à educação então vigente:

Segundo o Quadro 1, em quatro dos títulos aparecem as palavras "luta" e "lutar", há a menção a "resistir" e "resistência" em dois deles. Além de ser possível perceber a preocupação de conectar a educação a temas amplos que afligiam a socie-

\section{Quadro 1}

Títulos das Revistas n. 1 a 18 .

\begin{tabular}{|c|c|}
\hline Revista & Título da Revista \\
\hline n. 1 & O educador precisa ser educado \\
\hline n. 2 & Administração, poder e trabalho \\
\hline n. 3 & Pedagogia do oprimido, educação do colonizador \\
\hline n. 4 & Ilusão política, desilusão pedagógica \\
\hline n. 5 & Educador = Trabalhador \\
\hline n. 6 & Resistência/submissão \\
\hline n. 7 & Educaçáo e Imperialismo \\
\hline n. 8 & Educaçáo: instrumento de luta \\
\hline n. 9 & Educadores: a luta pela organização \\
\hline n. 10 & Educaçáo e política \\
\hline n. 11 & A luta pela autonomia contra a exclusão \\
\hline n. 12 & Quem paga a escola paga? \\
\hline n. 13 & Após as eleiçôes, o debate continua \\
\hline n. 14 & A crítica e a prática da educação \\
\hline n. 15 & Pensar a educação é pensar a sociedade \\
\hline n. 16 & Pensar a educaçáo é pensar a transformaçáo social \\
\hline n. 17 & Educar é preciso \\
\hline n. 18 & Educação: educar - saber - resistir - lutar \\
\hline
\end{tabular}

Fonte: elaboração própria. 
dade brasileira, como a dependência externa, na edição sobre Imperialismo e na que tratou da educação do colonizador; e profundos embates políticos na sociedade brasileira. No décimo primeiro editorial, coloca-se como ponto central da revista a luta pela auto-organização da classe assalariada em comissóes criadas nos próprios locais de trabalho. A ideia da insuficiência da crítica, a qual deve ser seguida por uma ação, é amplamente reforçada, assim como a visão da educação como instrumento de luta.

A preocupação em conectar o tema da educação a aspectos mais amplos sem perder de vista os problemas concretos está presente no editorial da Revista n. 4, em que se registra o retorno de Paulo Freire ao Brasil e o significado político de sua volta. Ainda nesse texto, ressalta-se a afirmação do educador que, ao chegar ao Brasil, declarou que seria necessário reaprender o Brasil e reinventar a educação brasileira. Apesar de ser uma citaçáo longa, é pertinente destacar aqui a parte deste editorial que corresponde a um instigante convite à construção do novo na educação brasileira, alertando para o risco das ilusóes políticas que se conectam às desilusões pedagógicas:

No caminho que leva ao encontro de soluçóes viáveis, sempre históricas, portanto, limitadas, vulneráveis, não faltarão, porém, ilusões e desilusóes. O ressurgimento do movimento sindical do professorado, notadamente dos professores de $1^{\circ}$ e $2^{\circ}$ graus, indica que o desafio está sendo enfrentado e o caminho está sendo feito, aberto: o educador reinventa a educação reorganizando sua classe, invadindo as ruas, levando a "Escola" para a praça. É um político enquanto educador. Não se reduz ao político do ato pedagógico. Descobre a dimensão política das metas pedagógicas a serem alcançadas. Neste percurso, a primeira tentação pedagógica é a própria ilusão política, que consiste numa falsa autonomização do político como autoexplicável. É o político "em si" e "para si". Dá-se quando o político oculta em nome de um discurso universal abstrato, os interesses de classe envolvidos. A ilusão política está ligada à desilusão pedagógica. Esta é produto dos rígidos enquadramentos da cultura nos canais burocráticos, diferenciando saber "legítimo" das academias, do "ilegítimo" provindo da massa não titulada. A pedagogia burocrática é o pilar dessa desilusão, dando ênfase no cumprimento rígido do programa, ao sistema de exames e à disciplinaçẫo do aluno. [...] $\mathrm{O}$ caminho até aqui percorrido por esta Revista nos permite chegar a um conjunto de novas ideias, novas implicaçôes a respeito do ato pedagógico. A passagem do micro para o macrossistema, a insistência na visão da totalidade, a ênfase no questionamento e na crítica como mecanismos para a superação da ingenuidade pode levar por outro lado, a privilegiar a abordagem política dos problemas e das propostas educacionais, deixando de lado as relaçóes pessoais e as questôes concretas, particulares. $\mathrm{O}$ geral não explica o particular como o particular náo explica o geral. Não podemos, por medo de náo enxergar a floresta, deixar de ver as pequenas árvores. Paradoxalmente, a conquista do político pode levar à desilusão pedagógica, isto é, à fuga na ilusão política. A desilusão se traduz 
hoje pelo sentimento de impotência e pela consequente inoperância, pela descrença e pela ausência de propostas concretas. A desilusão pedagógica é ainda explicável pelo arrocho pedagógico pelo qual passamos e ainda estamos passando, pelo aviltamento dos salários dos professores, transformados em sacerdotes pelo messianismo pedagógico, do regime militar. Essa desilusão pode, por isso mesmo, nos conduzir à ilusão política, igualmente ingênua. Diante da ilusão política e a desilusão pedagógica resta o "historicamente possível”, no dizer de Paulo Freire. Entenda-se, porém, esse "possível”, esse viável histórico. O possível não é o que é permitido ser feito, mas o que é conquistado, o que é projetado. Fazer o que é possível historicamente significa abrir possibilidades, ampliar e estender os espaços já conquistados. O possível é também a utopia de hoje que, graças a uma prática social transformadora de hoje, será a realidade de amanhã (EDUCAÇĀO \& SOCIEDADE, 1979b).

Assim, a Revista que surge segundo consenso entre aqueles que estáo no seu nascimento, abre-se como um espaço para o debate a respeito dos caminhos possíveis para a educação brasileira.

\section{A revista como espaço de debate e enfrentamento de ideias: expressão de um movimento mais amplo no campo educacional}

Conforme Vieira (1995), as páginas da Revista traduziram dilemas, contradiçóes e alternativas cabíveis desde os fins dos anos 1970, como publicação de uma das entidades-chave na organização do campo educacional. O CEDES, juntamente com as recém-criadas Associação Nacional de Pós-Graduação e Pesquisa em Educação (ANPED) e Associação Nacional de Educação (ANDE) organizaram as Conferências Brasileiras de Educação (CBE), que foram palco de intensos debates, com ampla participação de pesquisadores e trabalhadores da educação. As conferências constituíram importante espaço de discussão e reflexão, configurando-se como espaço de resistência e elaboração de propostas para as políticas educacionais. As discussóes trazidas pela Educação \& Sociedade, quando vistas em conexão com os debates da CBE, permitem dimensionamento mais adequado dos enfrentamentos de ideias e propostas, bem como caracterizam a Revista como um espaço de divergências. Na impossibilidade de realizar nesse espaço um exame detalhado da relação entre as ediçóes das CBE e as expressões destes debates na Revista, focalizamos aqui algumas conexões entre os registros da II CBE presente nos Anais do evento e as discussóes geradas na Revista no mesmo período.

A I CBE ocorreu em 1980, com o intuito de promover avaliação e crítica quanto ao cenário educacional à época. A II CBE aconteceu em 1982 na Universidade Federal de Minas Gerais (UFMG), sob o tema: "Educação: perspectivas na 
democratização da sociedade" (CBE, 1982, p. 7); o objetivo consistia em "enfatizar mais as discussóes sobre as novas perspectivas delineadas pelas atuais condiçóes políticas que o povo brasileiro vem conquistando, do que a simples avaliação e crítica da situação atual” (ANAIS II CBE, 1982, p. 7). Houve cerca de 2.200 participantes por dia, provenientes de todos os estados brasileiros e dos três graus de ensino.

O sociólogo Florestan Fernandes ${ }^{1}$, que na década de 1980 teve acentuada atuação na luta pela educação pública, foi convidado para realizar a abertura da II CBE e falou sobre a necessidade de um novo ponto de partida, que não seria o mesmo das lutas dos anos 1960 referente às reformas de base, já que a defesa da escola pública neste novo momento:

Renasce com a revitalização de processos histórico-sociais que pareciam banidos da cena histórica. [...] Hoje, não se trata mais, concretamente, de colocar o cidadáo no eixo da reflexão pedagógica transformadora. Hoje o que é necessário fazer para dar uma resposta criativa e um apoio decidido à regeneração da sociedade civil, provocada primordialmente pelas classes trabalhadoras, em seu movimento orgânico e espontâneo, consiste em tomar como eixo da reflexão e da ação pedagógicas a revolução social que está se desencadeando, a qual póe o operário, o trabalhador agrícola e o homem pobre - em síntese, os oprimidos - como o sujeito principal do processo educativo (FERNANDES, 1982, p. 23).

O agente responsável por estar à frente das propostas e da luta pela educação pública parece ter sido um dos alvos das discussóes realizadas na II CBE. Os debates passaram pelos dilemas a respeito do papel do intelectual e dos trabalhadores nesse processo. Verifica-se que esta passagem de Florestan Fernandes ressalta que entre o movimento dos escolanovistas e o início da década de 1980 há uma mudança significativa. Em 1982, tratava-se de colocar os oprimidos como sujeitos principais do processo educativo.

Outra importante referência intelectual no debate educacional, Maurício Tragtenberg, um dos autores mais frequentes nos primeiros anos da Educação \& Sociedade ${ }^{2}$ e membro do comitê editorial da Revista, faz uma defesa contundente de que o protagonismo nessa luta seja dos trabalhadores. Ele foi autor da proposta de uma mesa na II CBE com o título "Quando o operário faz a educação". A posição de Tragtenberg foi a seguinte:

A ideia central da mesa foi a seguinte: Não convidar intelectual para falar e sim ouvir operário. Porque não há lugar onde se fala mais de operário que a Universidade. Em movimento popular, em periferia, mas na hora de conferência, em simpósio, se fala sobre o trabalhador, ninguém convida o trabalhador para se apresentar. O que irrita é você ver muito "representante" de trabalhador. Geralmente da boca da pequena burguesia que é a nossa classe, falando em nome dele. Daí decorre uma sugestão construtiva aos outros companheiros das universidades: quando tiver simpósio, 
conferência, mesa redonda, debate, lembrar o seguinte: tem trabalhador que, apesar disso, pensa. Ele não só faz, pensa. É importante convidar trabalhador para se apresentar e não o Tragtemberg, a Chauí, ou não sei quem lá, ficar carismatizando essas coisas, que isso é fazer o jogo do sistema. Toda vez que você carismatiza alguém, você faz o jogo do sistema, e também você deixa de pensar e transfere a sua autonomia de pensar e agir para o "iluminado" que, você espera que "cague linha" que diga o que você tem que fazer. A ideia da mesa é essa: quando o trabalhador educa, é uma ideia central. O trabalhador deve se apresentar diretamente. Segundo, a outra ideia, o trabalhador é vanguarda dele mesmo e não precisa de padre, nenhum intelectual e nenhum "cagador de regra" para dizer a ele, o melhor caminho (TRAGTENBERG, 1982, p. 177).

Ao final da mesa, Maurício Tragtenberg sugeriu que fosse levada a proposta de uma moção para ser extraída da II CBE, contendo a defesa do ensino público e gratuito em todos os níveis, alegando-se que a estratégia do Ministério da Educação e Cultura (MEC) seria priorizar apenas um dos níveis, tornando os demais pagos. Portanto, contrário à ideia de que a $\mathrm{CBE}$ escrevesse um manifesto priorizando o primeiro, o segundo ou o terceiro grau.

Este posicionamento de Tragtenberg parece relacionar-se a uma polêmica ocorrida na discussão da mesa que tratou do tema: "O ensino público e gratuito", da qual participaram os professores Dermeval Saviani, Guiomar Nano de Melo, Manoel Lucena, Luiz Pinguelli Rosa e Osmar Magalhães, além de representantes da União Nacional dos Estudantes (UNE). Nessa ocasião, o professor Saviani defendeu como ideia central a necessidade de que a luta pela ampliação das verbas para a educaçáo deveria estar acompanhada de reivindicaçóes específicas, para que fossem tratados os aspectos prioritários e que as verbas educacionais não fossem direcionadas para programas compensatórios de nutrição, transporte, saúde escolar:

Trata-se, aí, de passar da luta genérica - da defesa do ensino público em si, da luta por mais verbas para a educação, in abstracto - para a defesa do ensino público a partir de determinados pontos de estrangulamento, a partir de reivindicaçóes específicas. Trata-se de defender o aumento das verbas para a educação de tal modo que essas verbas sejam destinadas à superação desses pontos de estrangulamento (SAVIANI, 1982, p. 25).

A Revista Educação \& Sociedade número 14 dá continuidade aos debates destacados da II CBE, por meio do editorial e de texto publicado no Jornal da Educação, que compôs essa ediçáo. Em tom bastante contundente, a Revista se posiciona a respeito do teor que devem ter as propostas para a educação brasileira:

Muitas das manifestaçóes desta nova crítica educacional tornam-se meras receitas pedagógicas, estranhas a qualquer movimento da vida. 
Confundem a história da receita com a receita da história! Como críticos da Educação Brasileira, responsáveis por já ampla produçáo intelectual sobre matéria educacional nos dias de hoje, vários deles acabam em elegias ao idealismo. Apenas aparentemente ligam-se aos sacrifícios e aos embates da maioria da população brasileira.

A crítica pela crítica comprova que a realidade educacional está errada, mas tal crítica se esgota aí mesmo. É imprescindível uma crítica que fuja ao radicalismo da classe média intelectualizada, e que repila o irracionalismo. É imprescindível uma crítica que exponha sinceramente alternativas aos problemas, de forma clara e simples, pondo uma luz na escuridão da Educação Brasileira, se não for possível iluminá-la por inteiro.

A prática educacional náo pode viver de mitos, ou melhor, não pode "ser da legião dos grandes mitos, transformando a juventude num exército de aflitos", como diz a canção. A prática educacional, ao contrário, precisa repousar-se na verdade dos atos concretos. Qualquer que seja o nível intelectual dos alunos e dos professores, dos mais humildes aos mais sofisticados, somente o exemplo dos atos coerentes com as palavras ditas em classe figura como a autêntica prática do ensino crítico, essência da educaçáo Libertária (EDUCAÇÃO \& SOCIEDADE, 1983, p. 6).

No Jornal da Educação, as professoras Célia Pezzolo de Carvalho e Doris Accioly e Silva escreveram sobre a mesa coordenada por Maurício Tragtenberg na II CBE e rechaçaram a não aprovaçáo na Assembleia-Geral da citada moçáo que defendia o ensino público e gratuito em todos os níveis:

A respeito da representatividade da moção, pensamos que, com cer-
teza, ela não representa mesmo a maioria dos educadores, pois de
outro modo a educaçáo e a sociedade brasileira seriam muito dife-
rentes do que são. Sob essa recusa percebemos os limites da cons-
ciência política de grande parte dos educadores e mais do que isso,
uma certa concepção política que em nada contribuía para o avanço
real de nossa prática em direção a uma sociedade verdadeiramente
democrática. Dizer que a proposta é utópica é ignorar que a relação
entre fins e meios é inseparável e que o futuro começa aqui e agora,
nascido de nossos passos. Como fazer escolhas no cotidiano se não
tivermos clareza quanto ao que queremos realizar? O projeto que
tivermos de uma sociedade indicará os rumos de nosso dia a dia,
pois criamos o amanhã a partir de nossa prática diária. Se conside-
rarmos, hoje, utópica a proposta de uma sociedade onde os traba-
lhadores tomam em suas mãos o destino da sociedade, realmente
estaremos afastando sempre para mais distante de nós o amanhã que
desejamos, uma sociedade onde a satisfaçáo das necessidades básicas
caminhe ao lado da beleza, da paz e da liberdade. Sabemos que, em
nosso mundo, a classe operária é a única capaz de concretizar um tal
projeto. Nosso papel é estar ao lado dela, colocando nossos conheci-
mentos ao seu dispor, solidarizando-nos com suas lutas autônomas e 
prefigurando assim, com nossos atos, o mundo que todos buscamos realizar. (CARVALHO; SILVA, 1982, p. 127-128).

Explicita-se, assim, o espaço da Revista Educação \& Sociedade como expressão do embate de ideias, em um profícuo debate intelectual que reuniu importantes nomes da intelectualidade educacional na reflexão sobre os caminhos possíveis para sociedade brasileira.

O entrelaçamento entre a Revista e o debate no campo educacional evidencia-se em sua conexão com as CBEs. Nos anos seguintes, tomará significativo espaço na publicação as discussóes em torno da elaboração da nova Constituição, que foi objeto de discussão na IV CBE, em 1986, ocorrida na Universidade Federal de Goiás. Da IV CBE resultou a Carta de Goiânia, documento que reivindicava a educação pública, laica, gratuita e de qualidade para todos, abrangendo educação infantil, inclusiva e de jovens e adultos. Além disso, o documento também se posicionou em relação aos recursos públicos, solicitando que esses fossem destinados apenas a instituiçóes públicas. A Carta, com tão importantes reivindicaçôes, serviu como documento de referência para a mobilização do Fórum Nacional em Defesa da Escola Pública no decorrer da Constituinte. As três revistas publicadas no ano de 1986 abarcaram a temática, por meio de artigos, debates, com especial destaque à Revista Educação \& Sociedade número 25, que dedicou o editorial ao tema, bem como publicou a referida Carta.

Esse já é o período da dita "Nova República", que se caracterizou pela saída dos militares do governo federal e da transição para o regime democrático. Com o fim da ditadura, a crítica contundente às ingerências do Estado na educação deixa de ocupar espaço na Revista; passam a ser temas centrais: a discussão em torno da legislação educacional, em especial, a elaboraçáo do tema da educação na Constituiçáo Federal e a formulação da nova LDB, assim como adquire destaque a temática que articula educação e trabalho em tempos de reestruturaçáo produtiva e de avanço do neoliberalismo.

\section{Temas em destaque na Revista Educação \& Sociedade a partir de 1989: LDB, relações entre educação e trabalho no novo contexto produtivo e críticas ao Estado neoliberal}

Nos editoriais da Revista dos anos de 1986, 1987 e 1988 esteve presente a temática da educação na Constituinte. Entre o chamamento para a participação dos educadores na IV CBE aos momentos em que já se mostravam difíceis os encaminhamentos na Constituinte, com o fortalecimento do privatismo, até o desfecho da formulação da constituição, quando o texto da Constituição já está formulado, o editorial expressa as conquistas e as perdas, bem como conclama para a articulação em torno da nova LDB que garanta a efetivação dos ganhos alcançados na Constituição: 
Não se pode hoje deixar de ressaltar o significado de avanços como a igualdade de acesso a permanência na escola, a gestão democrática de ensino público, a garantia legal para o pluralismo de ideias, de concepção pedagógica e de instituições de ensino, a valorização dos profissionais do ensino através da garantia de planos de carreira para o magistério público, em cada nível de ensino, contendo piso salarial profissional e ingresso exclusivamente por concurso público de provas e títulos. Este último tema, especialmente, acende uma chama de esperança pela sobrevivência da escola pública. Os educadores, já trôpegos pelo cansaço das constantes greves a que têm sido obrigados, para continuar em pé diante de seus alunos, querem agora acreditar na existência de uma carreira justa e de um salário digno para a categoria. Todavia, em paralelo aos avanços, devemos registrar também perdas ocasionadas fundamentalmente pelas condiçóes objetivas em que as negociaçóes foram possíveis. A destinação das verbas públicas para as escolas comunitárias confessionais ou filantrópicas continuará se configurando numa sangria aos cofres públicos e num incentivo a uma escola diferenciada para camadas diferenciadas da população.

[...] O CEDES [...] alerta seus leitores e associados para continuar a postos e vigilantes até que se promulgue não apenas a nova Constituição, como também a LDB. Neste sentido, marca encontro para todos os educadores e também os homens públicos, em Brasília, de 2 a 5 de agosto, quando a realizaçáo da $\mathrm{V}$ CBE deverá firmar os rumos da luta por uma LDB que garanta a implementação dos princípios da Nova Constituição (EDUCAÇÃO \& SOCIEDADE, 1988).

As edições seguintes da Revista, em especial até o número 34, no final de 1989, tiveram como tema central nos editoriais as articulaçóes pela nova LDB que foi o alvo da V CBE. Da quinta conferência derivou a Carta de Brasília, com as propostas dos 6.000 educadores lá presentes. Esta Carta foi publicada na edição de número 31 da Revista Educação \& Sociedade.

O cenário para as políticas públicas se complica a partir de 1989 com a intensificação da presença das ideias de cunho neoliberal norteando as açóes do Estado. Os editoriais da Revista registram este novo momento, bem como indicam as preocupaçóes que recaem sobre as decorrências do privilegiamento dos interesses financeiros em detrimento das questôes sociais, entre elas a educação:

O CEDES tem estado sempre atento ao que se passa na vida do país. Por isso não poderia deixar de externar a sua preocupação pela grave crise por que passa a educaçáo pública entre nós e as soluçóes de caráter privatista que o Ministério da Educação tem endossado. Trata-se de medidas inseridas no bojo das políticas de caráter conservador e neoliberal que tem inspirado o Governo Collor, cuja meta principal é derrotar a inflação com base no pressuposto de que esta é uma decorrência do déficit público e náo uma luta distributiva entre as classes sociais. Isto muito 
nos preocupa: sabemos que os países que adotaram o receituário neoliberal, de fato, tiveram os seus índices inflacionários diminuídos, porém a custa do aumento do desemprego, da miséria social das suas populaçóes e, portanto, da estagnaçáo das suas economias (EDUCAÇÃO \& SOCIEDADE, 1990a, p. 6).

Mercado e competição parecem ser os deuses dos novos tempos, matrizes da justiça, da liberdade e da riqueza (EDUCAÇÃO \& SOCIEDADE, 1990b, p. 5).

As fantasias neoliberais não são apenas fantasias. São armas ideológicas. E os projetos econômicos e sociais que desencadeiam são, literalmente e sem qualquer metáfora, máquinas de morte, com a justificativa mais social darwinista que se possa imaginar (EDUCAÇÃO \& SOCIEDADE, 1990b, p. 9).

A presença das ideias neoliberais inspirando as políticas estatais aparece como um dos temas importantes na Revista, que publicou um número especial sobre as "vicissitudes do pensamento liberal, em suas diversas vertentes", em 1996: “Teorias Críticas e Liberalismo. Contrastes e Confrontos” (EDUCAÇÃO \& SOCIEDADE, 1996).

As implicações entre neoliberalismo, reestruturação produtiva e os dilemas da qualificação perpassam um dos temas que se torna central na revista neste período: as relaçôes entre educação e trabalho.

Notou-se que houve intensa publicação e elaboração de investigaçóes que tratassem do tema educação e trabalho. No editorial da revista n. 32 é enfatizado que uma das vertentes da atuação do CEDES consiste na produção e difusão de pesquisas e os esforços voltam-se para esta temática. A partir do número 33 há a publicação sistemática de textos com esse assunto, bem como no número 41 e 45 todos os artigos da Revista focalizam essa discussão. O editorial da Educação \& Sociedade de número 41 esclarece o caminho tomado pela Revista:

A Revista Educação \& Sociedade tem tratado de oferecer aos seus leitores textos e artigos que dêem conta da discussão internacional desencadeada pelas mudanças ocorridas no modo de produzir de nossos dias.

Em seu número 33 Maria de Ibarrola trata das "Relaciones entre la escuela y el trabajo: discusión de enfoques y categorias de análisis". No número 34 aparecem dois artigos nesse sentido: "Novas tecnologias, perspectivas profissionais e autocompreensão cultural: desafios à formaçáo", de Martin Baethge e "La economia y el discurso sobre la educación", de Mariano F. Enguita. No número 35 acha-se incluído um artigo de Claus Offe sobre "Sistema educacional, sistema ocupacional. Política da educação - Contribuição à determinação das funçóes sociais do sistema educacional". No número seguinte da revista encontravam-se os artigos de Werner Markert acerca das "Novas formas de trabalho e cooperação na empresa" e de Humberto Muños Garcia e Maria Herlinda S. Zozaya, falando sobre "Educación y em- 
pleo". O artigo do pesquisador alemão Gero Lenhardt, intitulado "A formaçáo como finalidade da escola" faz parte do número 37 da revista, juntamente com o texto de Vanilda Paiva, "Produção, qualificação e currículos". No número 38 encontramos um trabalho de Birgit Mahnkopt: Em direção a uma modernizaçáo de política sindical centralizada na qualificação. Ainda sobre o tema temos, na revista 39, "Educação e bem-estar social" de Vanilda Paiva. Para completar essa relação retrospectiva sobre as publicaçóes acerca do tema, constatamos na revista 40 a presença do texto de Werner Market "Teoria crítica e teoria educacional Um esboço de uma teoria crítica da sociologia da educação da Alemanha” (EDUCAÇÃO \& SOCIEDADE, 1992).

Ainda no n. 52 da Revista é divulgado o programa conduzido pelo CEDES, intitulado "Ciência e tecnologia, qualificação e produção", constituído por um feixe de projetos de pesquisa conectados e desenvolvidos de forma cooperativa entre Universidades, o DIEESE e diversas ONGs. Assim:

O programa "Ciência e tecnologia, qualificação e produção" que ora se inicia no CEDES tem como pano de fundo as relações entre Educação e Trabalho no contexto da transformação produtiva em curso e suas consequências não apenas na área industrial, mas também sobre os serviços e as formas alternativas de inserção no mundo do trabalho que terão que se desenvolver diante do desemprego crescente provocado pela racionalização ligada à revolução microeletrônica. Considera ainda as significativas mudanças que vêm sendo introduzidas nos mecanismos de proteção social, como consequência da crise fiscal dos Estados e de novas concepçóes a respeito do próprio papel dos Estados e dos direitos dos cidadãos (EDUCAÇÃO \& SOCIEDADE, 1995, p. 418).

\section{Considerações finais}

A Revista Educação \& Sociedade constituiu-se como manifestação política pungente de repúdio à ditadura militar e sua política educacional, no contexto de refluxo da contrarrevolução e ascensão das várias frentes da luta social. Tornou-se meio de difusáo de ideias e espaço para debates que congregou intelectuais de diversos matizes teóricos e diferentes perspectivas políticas no campo progressista. Entre o consenso e as divergências que abrigou constitui documentação importantíssima para aqueles que estudam os mais variados temas na área, passando pela história da educação, políticas educacionais, teorias pedagógicas e os mais relevantes assuntos que conectam educação e sociedade.

A leitura dos editoriais permitiu acompanhar o engajamento dos membros que conduziram o periódico no movimento dos educadores dos anos 1980, 
nas Conferências Brasileiras de Educação, nos debates acerca da formulação da legislação pós-militar que fundamentaria toda a educação brasileira nos anos posteriores, além de, nos anos 1990, manifestar uma conexão mais sistemática com a pesquisa científica por meio da temática educação e trabalho.

\section{Notas}

1. O editorial da Revista Educação \& Sociedaden. 54 foi dedicado a homenagear Florestan Fernandes, falecido em 1996, com o seguinte título: Florestan Fernandes: o cotidiano do professor transformado em líder político.

2. Maurício Tragtenberg foi o mais assíduo autor da Revista Educação \& Sociedade até 1986. Docente na UNICAMP e defensor de uma linha libertaria de educação, escreveu sete artigos ao longo das vinte revistas, a maioria deles pautados em temas advindos de uma raiz anarquista, bem como educação integral, relações de poder na escola, sindicalismo e delinquência acadêmica (TRAGTENBERG, 1978; 1979a; 1979b; 1980; 1981; 1984; 1985a; 1985b).

\section{Referências}

CARVALHO, C.P. de; SILVA, D.A. Quando o operário faz a educação: reflexóes a partir da não aprovação de uma moção durante a II Conferência Brasileira de Educaçáo. Educação \& Sociedade, Campinas, n. 14, 1983.

CONFERÊNCIA BRASILEIRA DE EDUCAÇÃO (CBE), II, 1982, Anais... Belo Horizonte: UFMG, 1982.

CUNHA, L.A. Educação, Estado e Democracia no Brasil. São Paulo: Cortez, 1991.

EDUCAÇÃO \& SOCIEDADE. Campinas, n. 3, 1979a.

. Campinas, n. 4, 1979b.

. Campinas, 1983.

. Campinas, n. 29, 1988.

. Campinas, n. 35, 1990a.

. Campinas, n. 36, 1990 b.

. Campinas, n. 41, 1992.

EDUCAÇÃO \& SOCIEDADE. Campinas, n. 52, 1995.

. Campinas, n. 57, 1996.

FERNANDES, F. A revolução burguesa no Brasil. São Paulo: Globo, 2006 a.

O novo ponto de partida. In: CONGRESSO BRASILEIRO DE EDUCAÇÃO,

2., 1982. Anais... 1982.

. Pensamento e ação. O PT e os rumos do socialismo. São Paulo: Globo, $2006 \mathrm{~b}$. 
Que tipo de república? São Paulo: Globo, 2007.

FERREIRA JR., A.; BITTAR, M. A ditadura militar e a proletarização dos professores.

Educação \& Sociedade, Campinas, v. 27, n. 97, 2006. http://dx.doi.org/10.1590/S010173302006000400005

SAVIANI, D. O ensino público e gratuito. In: CONGRESSO BRASILEIRO DE EDUCAÇÃO, 2., 1982. Anais... 1982.

TRAGTENBERG, M. A delinquência acadêmica. Educação \& Sociedade, Campinas, n. 3, 1979a. n. $8,1981$.

. Educação e política: a proposta integralista. Educação \& Sociedade, Campinas, . Francisco Ferrer e a Pedagogia Libertária. Educação \& Sociedade, Campinas, n. 1, 1978.

. O conhecimento expropriado e reapropriado pela classe operária: Espanha 80 . Educação \& Sociedade, Campinas, n. 7, 1980.

. O discurso da servidão voluntária. Educação \& Sociedade, Campinas, n. 21, 1985a.

Quando o operário faz a educação. In: CONGRESSO BRASILEIRO DE EDUCAÇÃO, 2., 1982. Anais... 1982.

Relaçôes de poder na escola. Educação \& Sociedade, Campinas, n. 20, 1985b. http://dx.doi.org/10.1590/S0102-64451985000100021

. Sobre educação, política e sindicalismo. Educação \& Sociedade, Campinas, 1984.

. Violência e trabalho através da imprensa sindical. Educação \& Sociedade, Campinas, n. 2, $1979 \mathrm{~b}$.

VIEIRA, E. Editorial. Educação \& Sociedade, Campinas, n. 50, 1995.

Recebido em 16 de janeiro de 2018.

Aceito em $1^{\circ}$ de fevereiro de 2018. 